\title{
PERSISTENCE OF ANTIBIOTICS IN BLOOD OF PATIENTS WITH ACUTE RENAL FAILURE. II. CHLORAMPHENICOL AND ITS METABOLIC PRODUCTS IN THE BLOOD OF PA_ TIENTS WITH SEVERE RENAL DISEASE OR HEPATIC CIRRHOSIS * $\dagger$
}

\author{
By CALVIN M. KUNIN, $\ddagger$ ANTHONY J. GLAZKO § AND MAXWELL FINLAND
}

(From the Thorndike Memorial Laboratory, Second and Fourth (Harvard) Medical Services,
Boston City Hospital, and the Department of Medicine, Harvard Medical School,
Boston, Mass., and from the Research Division, Parke, Davis and Company,
Detroit, Mich.)

(Submitted for publication April 7, 1959; accepted May 1, 1959)

It is known that the kidney plays a major but variable role in the elimination of most of the antibiotics that are used systemically. Since these drugs are often employed in the prevention and treatment of infections in patients with severe renal disease, it becomes essential, both for the choice of agents and for their most effective use, to know how the different antibiotics are handled by the patient with impaired renal function. The present series of studies was therefore undertaken with a view to providing a basis for the rational choice of antibiotics and their dosage in such patients. The persistence of several other commonly used antibiotics in the blood of patients with anuria and severe renal impairment was described in other papers of this series $(2,3)$. This paper is concerned with the overall metabolism of chloramphenicol in similar patients. In addition, since the liver is also involved in the metabolism of chloramphenicol, studies in a few patients with severe hepatic cirrhosis are also included.

The structure of chloramphenicol and possible sites of chemical alterations as they occur in the body are shown in Figure 1. A summary of what is currently known about the metabolism of chloramphenicol in man is presented schematically in Figure 2. Following the adminstration of chlor-

* Aided in part by a grant (E-23) from the United States Public Health Service.

$\dagger$ An abstract of this paper has been published (1).

$\$$ Postdoctorate Fellow, National Institute of Allergy and Infectious Diseases. Present address: Department of Preventive Medicine, University of Virginia, Charlottesville, Va.

§ Biochemist, Research Division, Parke, Davis and Company. amphenicol by the oral or parenteral route, 75 to 90 per cent of the administered dose may be recovered in the urine of patients who have normal renal function $(4,5)$. From 5 to 15 per cent of the recovered drug is in the microbially active form; the remainder is composed largely of an inactive monoglucuronide conjugate and to a lesser extent products of hydrolysis (6). Aryl amine derivatives of chloramphenicol are not ordinarily detectable in the serum or urine of man. About 3 per cent of the administered dose of chloramphenicol is excreted into the bile $(4,7)$ but less than 1 per cent is recoverable in the feces, largely as aryl nitro and amine derivatives (4).

In sharp contrast to the situation in man, the principle pathway of excretion of chloramphenicol in the rat is by the biliary system (8). When the drug reaches the intestine of the rat, the glucuronide linkage is hydrolyzed by the action of the bacterial flora, regenerating chloramphenicol (9). The nitro group may also be reduced to an amine (9) which is partially reabsorbed and excreted into the urine (8). Up to 25 per cent of the administered dose may be recovered in the urine of rats as inactive aryl nitro and amine derivatives.

In the present study, the half-life of chloramphenicol in serum and the 24 hour urinary recovery of chloramphenicol and its metabolic products were determined following single intravenous injections of the drug. These values were used to compare the fate of chloramphenicol in patients with renal and hepatic disease with that in normal subjects. 


\section{MATERIALS AND METHODS}

Patients studied and drugs used. The patients in whom these studies were made include four who were anuric, 11 who had varying degrees of renal impairment but normal liver function, 11 with nutritional (mostly alcoholic) cirrhosis of the liver but without significantly reduced renal function and four normal subjects. The levels of chloramphenicol and its derivatives were determined in the serum of six additional anuric patients who had been receiving chloramphenicol therapeutically. For purposes of the present study, anuria is defined as the condition in which a uremic patient excretes less than $400 \mathrm{ml}$. of urine daily for three or more days. It was assumed that the creatinine clearance in anuric patients was less than $1 \mathrm{ml}$. per minute. The diagnosis of cirrhosis of the liver was based on clinical and laboratory findings and in many of the patients was confirmed by liver biopsy.

Chloramphenicol ${ }^{1}$ was supplied for intravenous use in ampules containing $500 \mathrm{mg}$. dissolved in $2 \mathrm{ml}$. of a 50 per cent aqueous solution of $\mathrm{N}, \mathrm{N}$-dimethylacetamide. The contents of one vial was diluted to $150 \mathrm{ml}$. in 5 per cent aqueous solution of dextrose and injected intravenously over a period of 15 to 20 minutes. Venous blood for the assays was drawn before and two hours after the injection and at convenient intervals thereafter; at least five specimens were obtained following each injection.

Assays for chloramphenicol and its derivatives. The concentration of antimicrobially active chloramphenicol in the serum and urine was determined by a turbidimetric assay using a strain of Shigella sonnei (10). Most of the control sera from jaundiced patients, however, were found to inhibit this organism; such sera were, therefore, assayed by the same method using Agrobacterium tumefaciens which was not inhibited by control sera. The concentration of total nitro compounds plus amines was determined by the titanous chloride reduction procedure

1 Supplied by Parke, Davis and Company as Chloromycetin ${ }^{\circledR}$ solution.

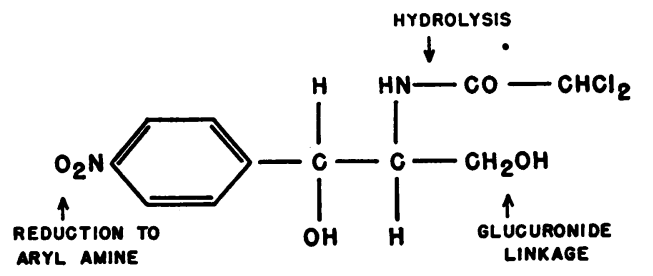

Fig. 1. Sites of Metabolic Alterations in StrucTURE OF CHLORAMPHENICOL

(11) ; the aryl amines were determined on the same filtrates by the method of Bratton and Marshall (12) and the concentration of nitro compounds was calculated by the difference. All results are expressed in terms of chloramphenicol equivalents.

Identification of chloramphenicol and its products. Chloramphenicol glucuronide was identified in urine and in serum filtrates by paper chromatography using the descending procedure with butanol-phenol-pyridine solvent described elsewhere (6). The urine was applied directly to the paper strips; the serum was first deproteinized with five volumes of ethanol, centrifuged, and the supernatant concentrated by evaporation at room temperature. A known sample of chloramphenicol glucuronide (6) was used for comparison of $R_{t}$ values; the presence of this compound in the unknown samples was confirmed by the addition of $\beta$-glucuronidase which resulted in the regeneration of microbially active chloramphenicol. After chromotography, the location of the aryl nitro compounds on the paper strips was established by reduction with titanous chloride, bromination, diazotization and coupling (6).

The following terms are therefore used in this paper to describe chloramphenicol and its metabolic derivatives: 1) Microbially active chloramphenicol, as determined in the turbidimetric assays; 2) Aryl amine derivatives, indicating the value determined by the Bratton-Marshall method; and 3) Total nitro compounds, which includes the microbially active drug plus the inactive nitro derivatives.

Calculations of half-life and clearances. The serum

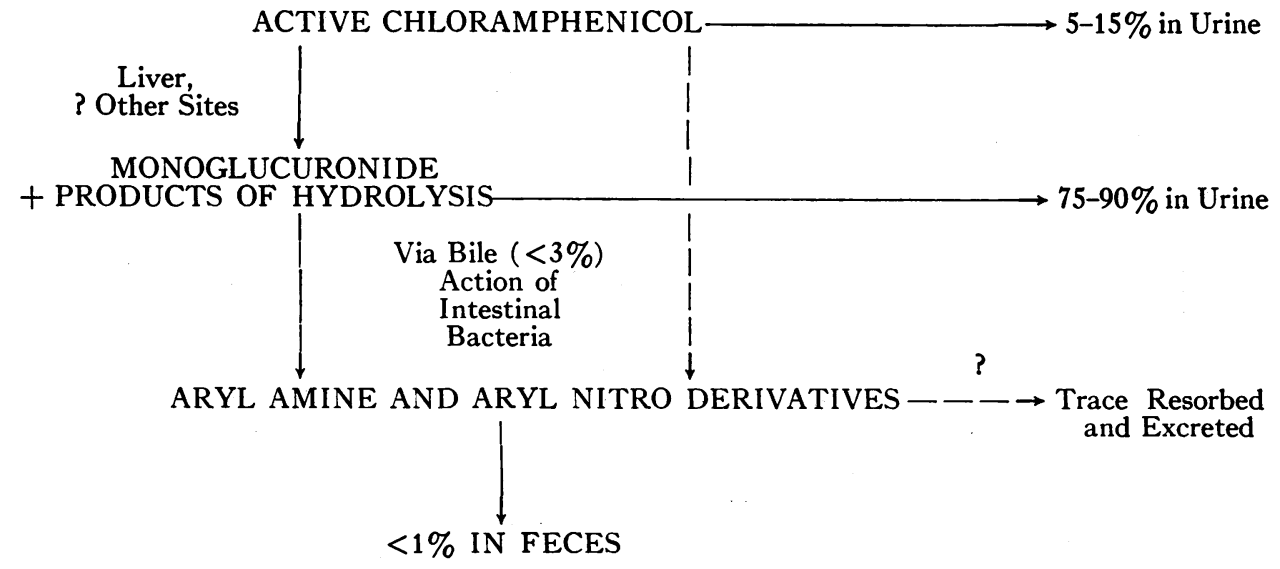

Fig. 2. Metabolism of Chloramphenicol in Normal Man 


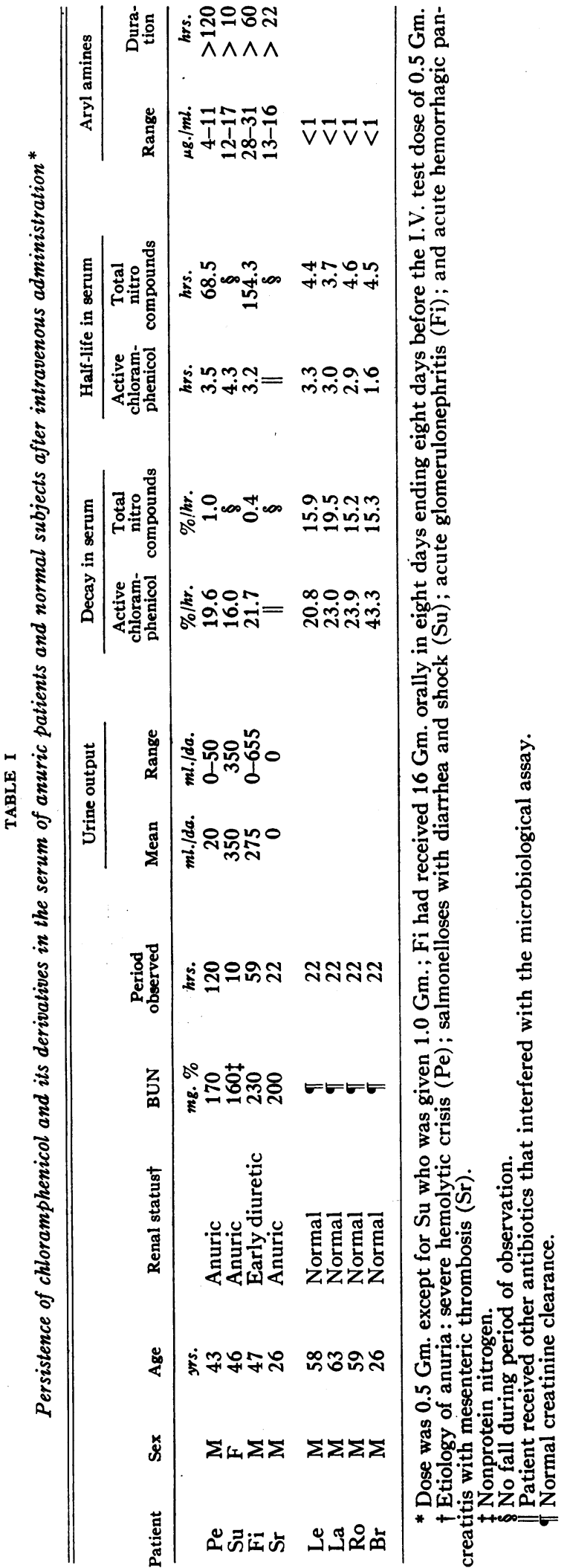

half-life $(T / 2)$ was calculated by the method of least squares (13). The degree of renal impairment was estimated from the 24 hour endogenous creatinine clearance (Ccr) (14), a modification of the method of Bonsnes and Taussky (15) being used to determine the concentration of creatinine in serum and urine.

Dialysis by the Kolff-coil artificial kidney was performed for therapeutic purposes in three anuric patients, the extraction ratio (ER) of creatinine and chloramphenicol being determined as in the previous paper (3).

\section{RESULTS}

Anuric patients

Table I presents data on four anuric patients and four normal subjects who were given a dose of chloramphenicol intravenously. The half-life of the microbially active drug in the serum of anuric patients does not differ greatly from that observed in the the normal subjects. In contrast, the serum half-life of the nitro compounds is markedly prolonged in the anuric patients over that found in the normals. In addition, aryl amines which are usually $<5 \mu \mathrm{g}$. per $\mathrm{ml}$. in serum of patients with normal renal function, were present in the anuric patients at levels ranging from 4 to $31 \mu \mathrm{g}$. per $\mathrm{ml}$. and persisted for long periods. It is not known whether this is due to drug metabolites or to the presence of other substances.

Figure $3 \mathrm{~A}$ presents the serum levels of the active and total nitro compounds as determined in the four normal subjects following an intravenous injection of chloramphenicol. The peak levels of either component at two hours after the intravenous injection did not exceed $8 \mu \mathrm{g}$. per $\mathrm{ml}$. and at 24 hours little or none was demonstrable in the serum; aryl amines were not detectable. Figure 3B shows the serum levels in an anuric patient who received an intravenous injection of the same amount of drug. The microbially active component reached about the same levels at two hours and disappeared at about the same rate as in the normal subjects. The total nitro derivatives, however, rose to a level of 28 $\mu \mathrm{g}$. per ml. at six hours and then declined slowly, but were still detectable at 120 hours. The level of aryl amines was slightly elevated prior to treatment and rose steadily to $11 \mu \mathrm{g}$. per $\mathrm{ml}$. (chloramphenicol equivalent) at 120 hours.

The latter patient had received procaine penicil- 


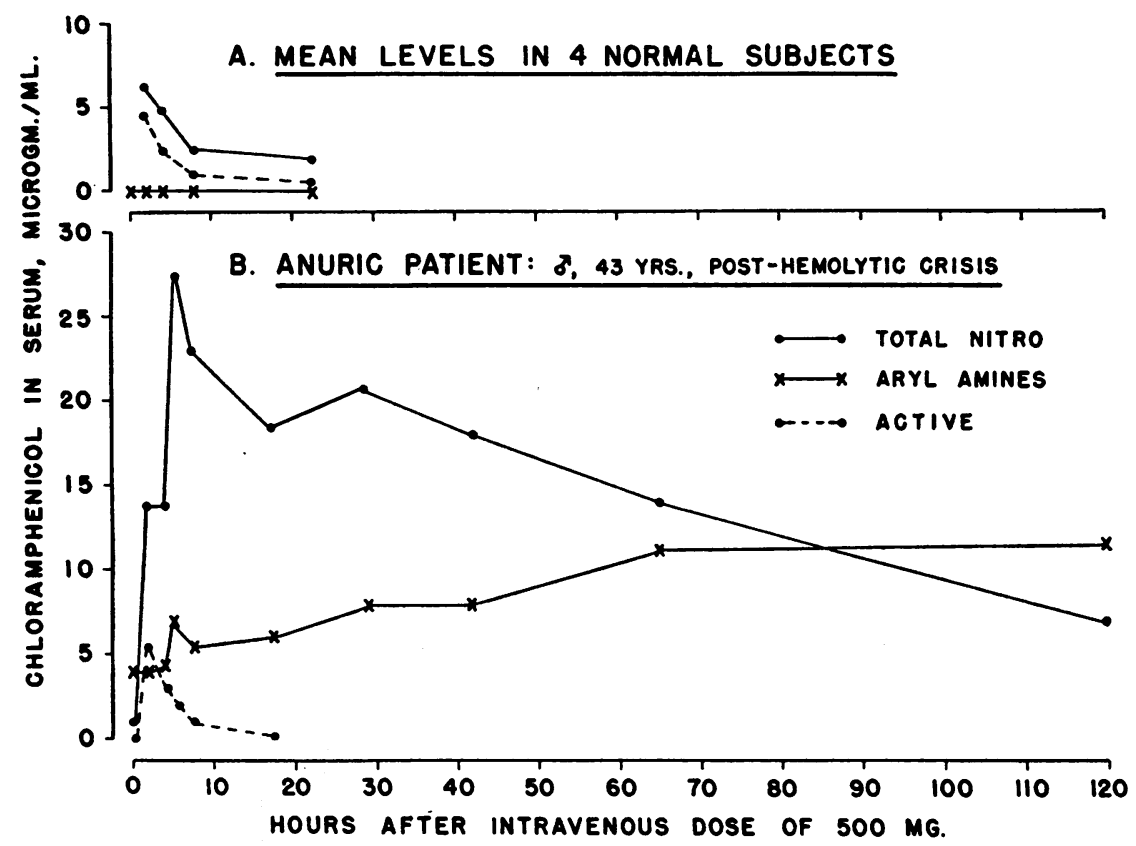

Fig. 3. Mean Levels of Chloramphenicol and its Metabolic Products in Serum

A) Four patients with normal renal function, and B) an anuric patient after a single intravenous dose of $500 \mathrm{mg}$. of chloramphenicol.

lin for several days up to 18 days prior to this study; the possibility was therefore considered that this might have accounted for the finding of aryl amines in this patient's serum prior to the administration of the chloramphenicol. In order to obtain further data on this possibility and also to determine whether uremia per se could give rise to substances in the serum that react like aryl amines in the Bratton-Marshall method, sera were obtained from 12 uremic patients who had not received chloramphenicol. Levels of aryl amines, equivalent to 1 to $38 \mu \mathrm{g}$. of chloramphenicol per $\mathrm{ml}$. were demonstrated in these sera. In most of these patients, however, there was a history of administration of some drug which gave a positive test for amines such as procaine (usually as procaine penicillin) or chlorothiazide. Previous administration of other aryl amines that are diazotized in this method, such as sulfonamides, acetazolamide and para-aminobenzoic acid, could not be excluded in all cases and many of these patients had minor surgical procedures during which procaine was injected. For these reasons, additional sera were obtained from seven uremic patients (nonprotein nitrogen values ranging from 63 to $165 \mathrm{mg}$. per $100 \mathrm{ml}$.) in whom previous administration of such substances could definitely be excluded. In most of these sera the level of aryl amines was less than $1.0 \mu \mathrm{g}$. per $\mathrm{ml}$. and the highest value was $1.5 \mu \mathrm{g}$. per $\mathrm{ml}$. It was therefore concluded that the finding of aryl amines in the blood of the uremic patients usually resulted from the administration of substances containing this moiety and their retention in the blood.

\section{Patients with varying degrees of renal impair- ment}

The mean half-life of active chloramphenicol and of the total nitro compounds was calculated for 11 patients with varying degrees of renal impairment. These data together with those of Table I are presented and correlated with the creatinine clearances in Figure 4 . The serum half-life of the microbially active compound was not greatly altered by the severity of the renal disease as reflected in the level of creatinine clearance. On the other hand, the half-life of the total nitro compounds was prolonged when the creatinine clearance fell below $20 \mathrm{ml}$. per minute. In many of the uremic patients, the peak levels of nitro compounds in the serum was not reached 


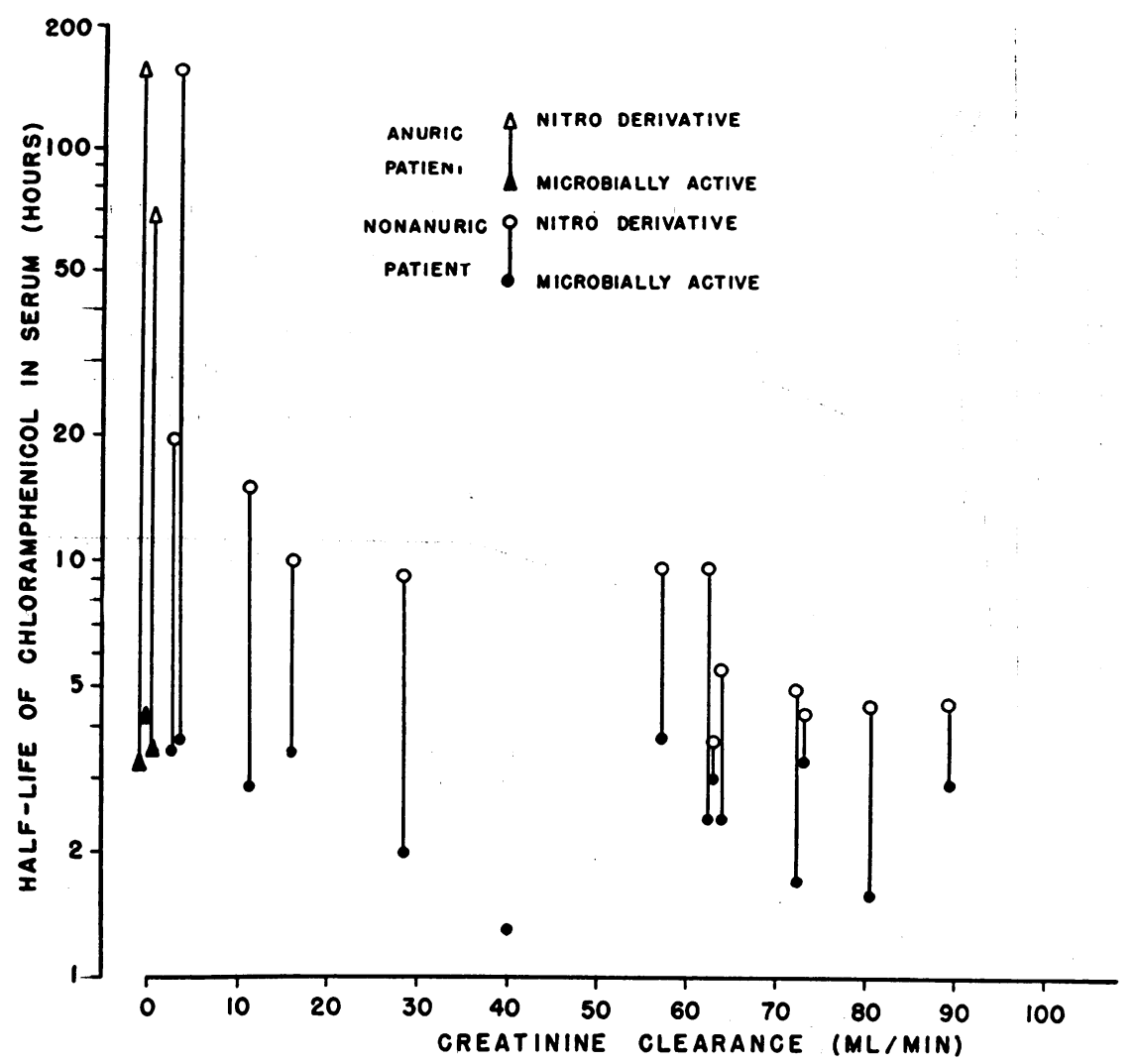

Fig. 4. Half-life of Microbially Active Chloramphenicol and of Total Nitro Compounds as Related to Creatinine Clearance in the Serum of Patients with Normal Renal Function and in Those with Varying Degrees of Renal IMPAIRMENT

until five to 10 hours after administration of the drug; the reason for this was not determined, but it may be due to a difference in the relative volume distribution of chloramphenicol and its monoglucuronide. It has been shown that chloramphenicol is concentrated in tissues, whereas the glucuronide is water soluble and presumably is distributed in the extracellular water $(4,16)$.
Accumulation of chloramphenicol in the blood of patients on continuous therapy

The results presented above suggest that active chloramphenicol given in ordinary doses is inactivated nearly as rapidly in patients with severe renal failure as in normal individuals, but that in the former the total nitro compounds may ac-

TABLE II

Levels of chloramphenicol and its derivatives in anuric patients receiving chloramphenicol for therapeutic purposes

\begin{tabular}{|c|c|c|c|c|c|c|c|c|}
\hline \multirow[b]{2}{*}{ Patient } & \multirow[b]{2}{*}{ Age } & \multirow[b]{2}{*}{ Sex } & \multirow[b]{2}{*}{ Etiology of renal failure } & \multirow[b]{2}{*}{$\begin{array}{c}\text { Days of } \\
\text { treatment }\end{array}$} & \multirow[b]{2}{*}{$\begin{array}{l}\text { Total } \\
\text { dose }\end{array}$} & \multicolumn{3}{|c|}{ Chloramphenicol in serum } \\
\hline & & & & & & Active & $\begin{array}{c}\text { Aryl } \\
\text { amine }\end{array}$ & $\begin{array}{l}\text { Total } \\
\text { nitro }\end{array}$ \\
\hline & yrs. & & & & $G m$ & $\mu g . / m l$. & $\mu g . / m l$. & $\mu g . / m l$. \\
\hline Sa. & 26 & M & Acute hemorrhagic pancreatitis & 2 & 4.0 & & 13 & 50 \\
\hline St. & 32 & $\mathbf{F}$ & Premature separation of placenta & 3 & 6.0 & 11.9 & & 158 \\
\hline & & & & 10 & 20.0 & 10.2 & $\begin{array}{l}47 \\
40\end{array}$ & $\begin{array}{l}611 \\
333\end{array}$ \\
\hline W. & 83 & F & $\begin{array}{l}\text { Ethylene glycol intoxication } \\
\text { Postoperative }\end{array}$ & 9 & $\begin{array}{r}8.5 \\
13.0\end{array}$ & $\begin{array}{l}25.0 \\
13.1\end{array}$ & & $\begin{array}{l}530 \\
189\end{array}$ \\
\hline $\mathrm{T}$ & 68 & $\mathbf{M}$ & Bladder perforation, shock & 14 & 13.0 & 12.3 & 31 & 134 \\
\hline F. & 47 & $\mathbf{M}$ & Acute glomerulonephritis & 8 & 16.0 & $<2.5$ & 28 & 50 \\
\hline
\end{tabular}




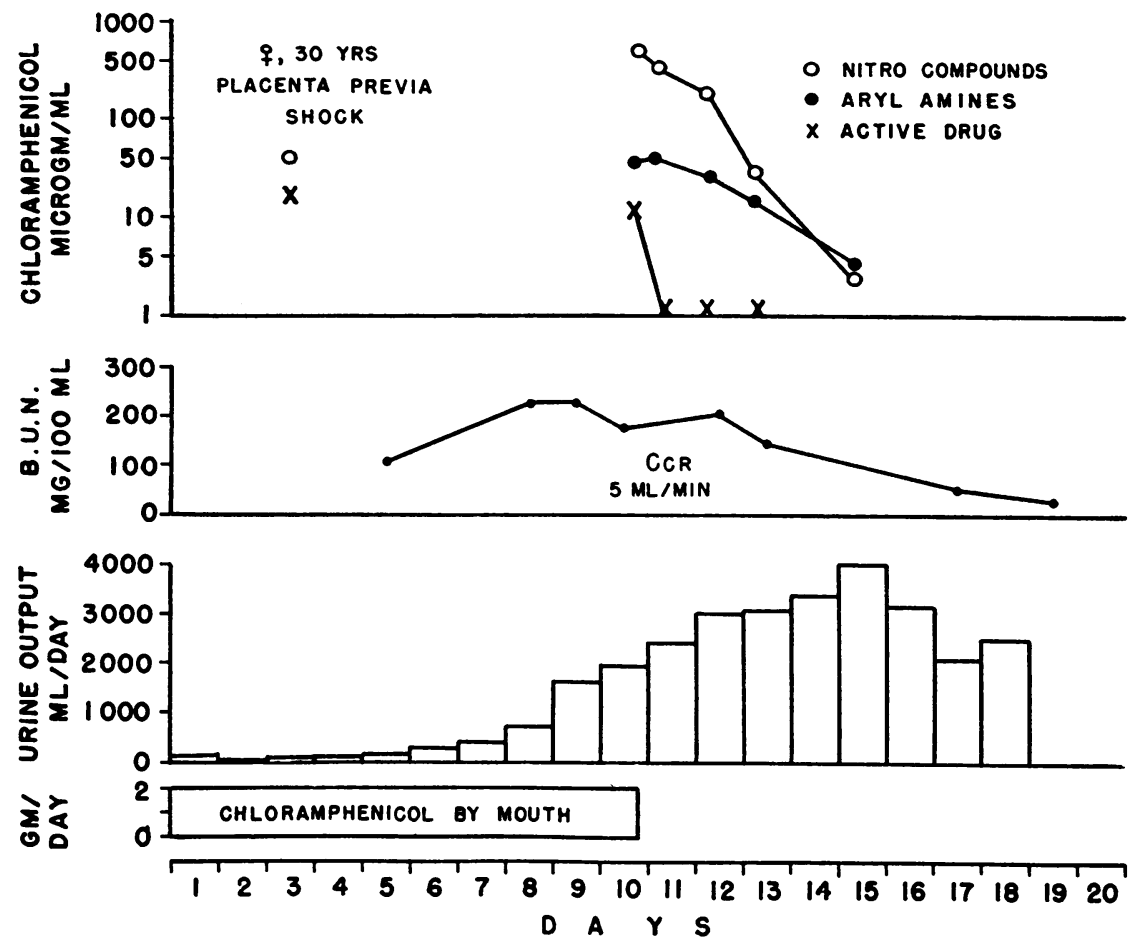

Fig. 5. Levels of Chloramphenicol and its Metabolic Products Obtained in the Serum of a Patient During the Diuretic Phase Following a Period of Anuria in the Course of Which she had been Treated with Chloramphenicol Orally

cumulate to very high levels. This is borne out by the data presented in Table II which shows the serum levels obtained during chloramphenicol therapy in six anuric patients. The highest level of active drug observed in this group was $23 \mu \mathrm{g}$. per $\mathrm{ml}$. in a patient who had been treated for seven days, whereas the highest level of the total nitro compounds and aryl amine derivatives noted in $\mathrm{Pa}$ - tient St. were 611 and $47 \mu$ g. per ml., respectively. The latter patient was in the diuretic phase of recovery and was no longer receiving the drug at the time the highest serum level was noted. The fall of chloramphenicol levels following cessation of therapy in this patient is illustrated in Figure 5 ; although the active drug was rapidly cleared from the serum, the total nitro compounds and the

TABLE III

Extraction of chloramphenicol and creatinine by the artificial kidney

\begin{tabular}{|c|c|c|c|c|c|c|c|}
\hline \multirow[b]{2}{*}{ Patient } & \multicolumn{3}{|c|}{ Chloramphenicol* } & \multicolumn{3}{|c|}{ Creatinine } & \multirow[b]{2}{*}{$\mathrm{A} / \mathrm{B} \times 100$} \\
\hline & Arterial & Venous & $\begin{array}{l}\text { Extraction } \\
\text { ratio (A) }\end{array}$ & Arterial & Venous & $\begin{array}{l}\text { Extraction } \\
\text { ratio (B) }\end{array}$ & \\
\hline $\begin{array}{ll}\text { Se } & \text { (a) } \\
\text { (b) }\end{array}$ & $\begin{array}{c}\mu g . / m l . \\
44 \\
39\end{array}$ & $\begin{array}{c}\mu g . / m l . \\
37 \\
34\end{array}$ & $\begin{array}{l}\% \\
16 \\
13\end{array}$ & $\begin{array}{c}m g . \% \\
22.0 \\
18.9\end{array}$ & $\begin{array}{c}m g . \% \\
15.2 \\
13.4\end{array}$ & $\begin{array}{l}\% \\
31 \\
29\end{array}$ & $\begin{array}{l}\% \\
52 \\
44\end{array}$ \\
\hline $\mathrm{Pe}$ & 7 & 4 & 43 & 22.0 & 5.0 & 77 & 56 \\
\hline $\begin{array}{r}\text { Ta (a) } \\
\text { (b) }\end{array}$ & $\begin{array}{l}131(22) \\
103(18.2)\end{array}$ & $\begin{array}{r}90(17.6) \\
100(15.0)\end{array}$ & $\begin{array}{r}31(20) \\
3(18)\end{array}$ & $\begin{array}{l}25.8 \\
17.4\end{array}$ & $\begin{array}{l}9.0 \\
8.4\end{array}$ & $\begin{array}{l}65 \\
52\end{array}$ & $\begin{array}{r}48(31) \\
6(35)\end{array}$ \\
\hline Mean & & & $21(19)$ & & & $51(59)$ & $41(33)$ \\
\hline
\end{tabular}

* Total nitro compounds were determined colormetrically. Data for the active chloramphenicol is shown in parentheses. 


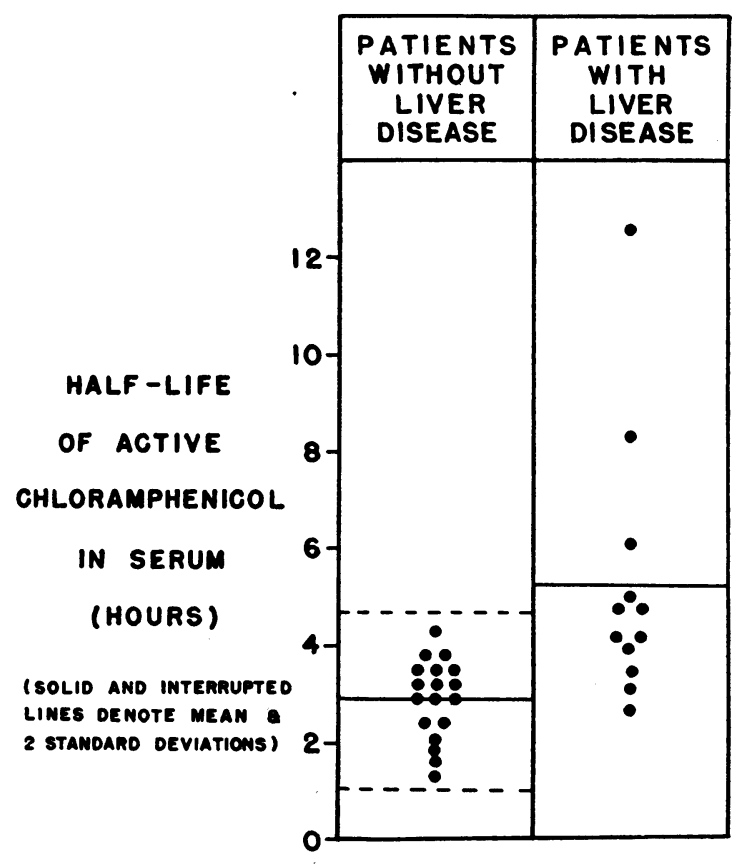

Fig. 6. Half-life of Microbially Active Chloramphenicol in the Serum of Patients With and Without Severe Liver Disease

aryl amines were removed more slowly. Paper chromatograhpy of the serum that showed the highest values for the total nitro compounds revealed that the major component had the same $R_{f}$ as an authentic sample of chloramphenicol glucuronide.

\section{Effect of hemodialysis with the artificial kidney} on chloramphenicol levels

Three anuric patients were subjected to hemodialysis by the artificial kidney (Kolff-coil type) for therapeutic purposes. The results, expressed as extraction ratio of the drug compared with that of creatinine, are presented in Table III. There was considerable variation in the extraction ratio of chloramphenicol and creatinine from one dialysis period to another. The comparative extraction of chloramphenicol and creatinine indicates that the nitro compounds were diffusible across the dialyzing membrane, but less so than creatinine. This may reflect the degree of binding of the nitro compounds to constituents of blood (16, 17). In general, the nitro compounds were cleared about half as well as creatinine and the microbially active drug probably about one-third as well. There is no ready explanation for the low extraction of total nitro compounds in the second series of observations in Patient Ta.

\section{Effect of liver disease on the serum half-life and excretion of chloramphenicol}

Eleven patients, all of whom had advanced cirrhosis of the liver, were each given $500 \mathrm{mg}$. of chloramphenicol intravenously; three of these patients had ascites and 10 had elevated levels of serum bilirubin. The half-life of active chloramphenicol in the serum of these 11 patients is shown in Figure 6 ; results of similar determinations in patients without cirrhosis of the liver, but with varying degrees of renal impairment are also shown in this figure for comparison. The mean serum half-life of active chloramphenicol in the patients without liver disease was $2.9 \pm 0.9$ hours. Among the patients with cirrhosis, there were marked differences in the serum half-life of the active drug, but at least three of the 12 observations showed a marked prolongation of the halflife over the normal values. The cirrhotic patient with the lowest serum half-life was the only one who was not jaundiced. However, the correlation between the serum half-life of active chloramphenicol and the total bilirubin level was imperfect; the correlation coefficient was +0.54 , significant at the 5 per cent level, suggesting that factors in severe liver disease other than total bilirubin retention may be involved in the abnormal metabolism of chloramphenicol.

Table IV lists the total amounts of chloramphenical and its products recovered in the urine of six patients with hepatic cirrhosis during the 24 hours following intravenous administration of $500 \mathrm{mg}$. of chloramphenicol. Chromatographic analysis demonstrated high concentrations of glucuronide in these urines. Although three of these patients had clearances of creatinine that were below normal, the overall recovery of the drug was comparable to that reported for normal individuals $(4,5)$; this was true for active chloramphenicol as well as for the total nitro compounds. The defect in chloramphenicol metabolism in the patients having the longer serum halflife of active chloramphenicol therefore appears to be a reduced rate of conversion of active drug 
to inactive products rather than a reduction in the total amount of drug converted.

\section{DISCUSSION}

The data presented in this study on the persistence of chloramphenicol and its metabolic products in the serum of patients with severe renal or hepatic disease confirm and extend observations made in previous investigations in normal man $(4,5,7)$. The observation that the serum half-life of microbially active drug is not signifcantly prolonged in anuric patients indicates that the rate of removal of the drug by conversion to its metabolic products is virtually unaffected by renal disease. The prolonged serum half-life and the accumulation of the metabolic products in uremic patients imply that the rate of removal other than by renal mechanisms must be quite slow; in anuric patients it probably proceeds at less than 1 per cent per hour.

The prolongation of the serum half-life of chloramphenicol metabolites as the creatinine clearance falls is not as striking as that noted with tetracycline (3). This is presumably due to the fact that the chloramphenicol residues are cleared not only by glomerular filtration, but by active tubular secretion as well (4). Although there is generally a parallel decline in tubular function with falling glomerular filtration rates in uremic patients (18), this may not be adequately reflected in estimations of the glomerular filtration rate as determined by the creatinine clearance. The anuric patient, however, has a profound loss of tubular as well as glomerular functional capacity which may explain the abrupt change in the halflife of the chloramphenicol products in anuric patients as noted in Figure 4.

The study of chloramphenicol metabolism in patients with liver disease was hampered by the unexpected inhibitory action of serum from jaundiced patients on the test organism, Shigella sonnei. This was remedied, in part, by the use of Agrobacterium tumefaciens which was less affected by these sera. Some of the patients with cirrhosis converted chloramphenicol to its metabolic products more slowly than did normal or uremic patients. Despite this somewhat slower conversion rate as estimated by the decline in serum of the active drug, about the same total and fractional amounts of chloramphenicol and its products were recovered in the 24 hour urine collections. Since abundant chloramphenicol glucuronide was recovered in these urines, it would appear that the patients with cirrhosis are capable of conjugating chloramphenicol. Thus, the defect noted in these patients was in the rate of conversion rather than in the total amount converted. Similar results have been reported in patients with liver disease given a salicylamide load (19). Such findings emphasize the need for determining the rate of glucuronide synthesis rather than the total amount synthesized.

From the data presented, it would appear that one approach to achieving greater antibacterial activity of chloramphenicol in blood or urine would be to reduce the extent to which the drug is conjugated with glucuronic acid. $\mathrm{N}$-acetylpara-aminophenol (NAPA) has been reported to be conjugated with glucuronic acid to a much

TABLE IV

Urinary recovery of chloramphenicol and its products in patients with hepatic cirrhosis during 24 hours following an intravenous dose of $500 \mathrm{mg}$.

\begin{tabular}{|c|c|c|c|c|c|c|c|c|}
\hline \multirow[b]{2}{*}{ Patient } & \multirow[b]{2}{*}{$\begin{array}{c}\text { Total } \\
\text { bilirubin }\end{array}$} & \multirow[b]{2}{*}{ Ccr } & \multicolumn{3}{|c|}{ Chloramphenicol in urine } & \multicolumn{3}{|c|}{ Recovered in urine } \\
\hline & & & Active & $\begin{array}{c}\text { Aryl } \\
\text { amine* }\end{array}$ & $\begin{array}{l}\text { Total } \\
\text { nitro }\end{array}$ & Active & $\begin{array}{c}\text { Aryl } \\
\text { amine }\end{array}$ & $\begin{array}{l}\text { Total } \\
\text { nitro }\end{array}$ \\
\hline $\begin{array}{l}\mathrm{Hi} \\
\mathrm{Bu} \\
\mathrm{Da} \\
\mathrm{Wa} \\
\mathrm{St} \\
\mathrm{Mr}\end{array}$ & $\begin{array}{c}\text { mg. \% } \\
2.8 \\
4.4 \\
0.3 \\
3.5 \\
1.8 \\
3.9\end{array}$ & $\begin{array}{r}\text { ml. } / \min . \\
45.5 \\
76.0 \\
82.0 \\
80.7 \\
103.1 \\
62.0\end{array}$ & $\begin{array}{l}m g . \\
66 \\
39 \\
78 \\
62 \\
71 \\
41\end{array}$ & $\begin{array}{l}m g . \\
23 \\
16 \\
25 \\
30 \\
32 \\
28\end{array}$ & $\begin{array}{l}\text { mg. } \\
355 \\
325 \\
433 \\
325 \\
417 \\
333\end{array}$ & \begin{tabular}{r}
\multicolumn{1}{c}{$\%$} \\
13.2 \\
7.7 \\
15.7 \\
12.2 \\
14.3 \\
8.2
\end{tabular} & $\begin{array}{c}\% \\
4.6 \\
3.2 \\
5.0 \\
6.0 \\
6.4 \\
5.6\end{array}$ & $\begin{array}{c}\% \\
71.0 \\
65.0 \\
86.6 \\
65.0 \\
83.4 \\
66.7\end{array}$ \\
\hline Mean & 2.8 & 74.9 & 60 & 26 & 365 & 11.9 & 5.1 & 73.0 \\
\hline
\end{tabular}

* Normal urinary amines are included in these determinations. 
greater extent than are salicylamide or acetylsalicylic acid (20). Corte and Johnson (21) also have reported that the administration of NAPA in doses of $250 \mathrm{mg}$. per $\mathrm{Kg}$. to rabbits given together with cortisol or prednisolone resulted in a marked increase in plasma levels of 17 hydroxycorticoids which, like many other substances, are inactivated to a large extent by glucuronide formation (22). In a preliminary brief study carried out in two normal subjects, the administration of NAPA ${ }^{2}$ did not appear to influence the metabolism of chloramphenicol to any significant degree. It is possible that more prolonged therapy or larger doses of either or both drugs, as compared with those used in this trial, may be necessary before an effect of NAPA can be demonstrated. Schmid and Hammaker (23), however, have recently shown that prolonged administration of NAPA may actually augment glucuronide production. In view of their findings it may be very difficult to overcome the glucuronidization mechanism by this type of competitive inhibition.

Chloramphenicol appears to be readily conjugated with glucuronic acid. Even where indirect bilirubin levels are high, suggesting poor conjugation of this substrate, large amounts of chloramphenicol glucuronide may be formed. It has been reported that the cat does not form glucuronates of phenolic substrates such as borneol, menthol, etc. (24). However, in other studies, oral administration of chloramphenicol to the cat has resulted in the excretion of large quantities of its glucuronide in the urine (25). Similiar experiments carried out in these laboratories with a strain of rats (26) that had been found deficient in the glucuronic acid conjugating mechanism for bilirubin, gave chromatographic evidence for the presence of chloramphenicol glucuronide in the urine following administration of chloramphenicol. ${ }^{8}$ It is possible that the primary alcohol group as present in chloramphenicol is more readily conjugated than phenolic compounds or bilirubin.

The aryl amine derivatives of chloramphenicol are ordinarily present in very low concentrations in the serum or urine of patients under treatment

\footnotetext{
${ }^{2}$ Supplied as Atasol, Frank Horner, Ltd., Montreal, Canada.

$3 \mathrm{We}$ are indebted to Dr. Rudi Schmid for providing the Gunn rats for this study.
}

(4). They appear gradually in the serum of uremic patients. The presence of aryl amines in the serum of uremic patients resulting from the administration of chloramphenicol invites comparisons with the situation in the rat in which large amounts of the aryl amine derivatives are excreted into the feces and urine. This has been shown to be the result of an active entero-hepato-renal circuit in the rat where nitro derivatives are excreted into the bile, reduced by the enteric flora to aryl amines and reabsorbed and excreted through the kidneys (8). Although in humans, only small amounts of chloramphenicol are excreted into the bile $(4,7)$, larger amounts may eventually get into the bile when renal clearances are markedly reduced. This may account for the gradual accumulation of aryl amine derivatives in the blood of uremic patients. It is also possible that reduction of the nitro group may occur in organs others than the gastrointestinal tract (4).

The accumulation of inactive chloramphenicol products in the blood of uremic patients raises the question of their potential toxicity for such patients. Chloramphenicol has been implicated as a causative factor in some cases of aplastic anemia (27-32). Since uremic patients are usually also anemic, further bone marrow depression that might result from chloramphenicol or its products may be difficult to detect. Of interest in this regard is a recent report of 15 patients observed during chloramphenicol administration in which five patients showed a reduced incorporation of iron into hemoglobin on the basis of which it was suggested that this drug may produce subclinical bone marrow depression (33). Although the possible role of renal impairment in these cases was not discussed, three of the five patients were listed as having renal disease, and two of the remaining 10 who showed no adverse effect from chloramphenicol are also listed as having some disease of the kidney.

Evidence has accumulated that at and soon after birth there is a deficient glucuronide forming mechanism (34-38). There is also a reduced tubular and glomerular functional capacity (39, 40) as compared with that of older children and adults. It would therefore be expected that both chloramphenicol and its products would be removed from the blood more slowly in those infants than in older children (41). 
Dialysis by the artificial kidney has been shown to reduce serum levels of both chloramphenicol and its nitro derivatives. Removal of large amounts of the drug by this method is hampered by the fact that the total nitro compounds are removed only about one-half as well as creatinine and even less of the active drug may be extracted.

Although the data on uremic patients indicates that normal dosage schedules must be used with chloramphenicol to maintain adequate therapeutic levels, the accumulation of inactive metabolic products introduces a new factor that must be considered. Although chloramphenicol glucuronide appears to be less toxic than the parent compound, the potential toxicity of the aryl amines is unknown. The hazards of administration of any drug to uremic patients must be recognized when the normal routes of elimination are unavailable. More serious results might be expected with compounds such as streptomycin which are normally excreted unchanged or with drugs whose metabolic products are more toxic than the original substance.

In patients with known hepatic impairment the overall metabolism of chloramphenicol appears to be essentially normal even though the rate of conjugation with glucuronic acid may be reduced. When renal function is adequate in cirrhotic patients, the prolongation of serum half-life does not appear to be great enough to justify any change from the usual dosage regimens.

\section{SUM MARY}

1. The serum half-life of active chloramphenicol is not significantly prolonged in anuric patients; on the other hand, the half-life of the metabolic products of chloramphenicol is markedly extended in patients with severe renal disease.

2. Small amounts of aryl amine derivatives may accumulate slowly in the blood of uremic patients receiving chloramphenicol.

3. Some patients with cirrhosis of the liver were found to have a prolongation of the serum half-life of active chloramphenicol. This appeared to be due to a slower rate of glucuronide conjugation in these patients.

4. Aryl nitro compounds of chloramphenicol were found to be extracted by the artificial kidney about one-half as well as creatinine.
5. These findings are discussed in relation to the potential toxicity of chloramphenicol products in uremic patients and in regard to dosage in patients with renal or hepatic disease.

\section{ACKNOWLEDGMENT}

The authors are indebted to Dr. John P. Merrill, Peter Bent Brigham Hospital, for permission to study several of his patients, including those subjected to hemodialysis, and for the creatinine determinations performed in his laboratory. The helpful advice of Dr. Rudi Schmid is gratefully acknowledged. The colormetric assays were performed by Miss T. Kaczala and Mr. E. Thompson, and the microbial assays were done by Mrs. M. Galbraith in the laboratories of Parke, Davis and Company. The creatinine determinations were done by Miss Judy Crouch.

\section{REFERENCES}

1. Kunin, C. M., Glazko, A. J., and Finland, M. Persistence of chloramphenicol and its metabolic products in blood of patients with renal or hepatic disease (abstract). Clin. Res. 1959, 7, 268.

2. Kunin, C. M., and Finland, M. Persistence of antibiotics in blood of patients with acute renal failure. III. Penicillin, streptomycin, erythromycin and kanamycin. J. clin. Invest. 1959, 38, 1509.

3. Kunin, C. M., Rees, S. B., Merrill, J. P., and Finland, M. Persistence of antibiotics in blood of patients with acute renal failure. I. Tetracycline and chlortetracycline. J. clin. Invest. 1959, 38, 1487.

4. Glazko, A. J., Wolf, L. M., Dill, W. A., and Bratton, A. C., Jr. Biochemical studies on chloramphenicol (Chloromycetin). II. Tissue distribution and excretion studies. J. Pharmacol. exp. Ther. 1949, 96, 445.

5. Chittenden, G. E., Sharp, E. A., VonderHeide, E. C., Bratton, A. C., Glazko, A. J., and Stimpert, F. D. The treatment of bacillary urinary infections with Chloromycetin. J. Urol. (Baltimore) 1949, 62, 771.

6. Glazko, A. J., Dill, W. A., and Rebstock, M. C. Biochemical studies on chloramphenicol (Chloromycetin). III. Isolation and identification of metabolic products in urine. J. biol. Chem. 1950, 183, 679.

7. Woodward, T. E., Smadel, J. E., and Ley, H. L., Jr. Chloramphenicol and other antibiotics in the treatment of typhoid fever and typhoid carriers. J. clin. Invest. 1950, 29, 87.

8. Glazko, A. J., Dill, W. A., and Wolf, L. M. Observations on the metabolic disposition of chloramphenicol (Chloromycetin) in the rat. J. Pharmacol. exp. Ther. 1952, 104, 452.

9. Smith, G. N., and Worrel, C. S. The decomposition of Chloromycetin (chloramphenicol) by microorganisms. Arch. Biochem. 1950, 28, 232. 
10. Joslyn, D. A., and Galbraith, M. Turbidimetric method for the assay of antibiotics. J. Bact. 1950, 59, 711.

11. Glazko, A. J., Wolf, L. M., and Dill, W. A. Biochemical studies on chloramphenicol (Chloromycetin). I. Colorimetric methods for the determination of chloramphenicol and related nitro compounds. Arch. Biochem. 1949, 23, 411.

12. Bratton, A. C., and Marshall, E. K., Jr. A new coupling component for sulfanilamide determination. J. biol. Chem. 1939, 128, 537.

13. Kunin, C. M., and Finland, M. Demethylchlortetracycline: A new tetracycline antibiotic that yields greater and more sustained antibacterial activity. New Engl. J. Med. 1958, 259, 999.

14. Smith, H. W. Principles of Renal Physiology. New York, Oxford University Press, 1956.

15. Bonsnes, R. W., and Taussky, H. H. On colorimetric determination of creatinine by the Jaffé reaction. J. biol. Chem. 1945, 158, 581.

16. Glazko, A. J., Wolf, L. M., and Dill, W. A. Distribution of chloramphenicol (chloromycetin) and its metabolic products between human red cells and plasma. Proc. Soc. exp. Biol. (N. Y.) 1949, 72, 602.

17. Smith, R. M., Joslyn, D. A., Gruhzit, O. M., McLean, I. W., Penner, M. A., and Ehrlich, J. Chloromycetin: Biological studies. J. Bact. 1948, 55, 425.

18. Bradley, S. E., Bradley, G. P., Tyson, C. J., Curry, J. J., and Blake, W. D. Renal function in renal diseases. Amer. J. Med. 1950, 9, 766.

19. Barniville, H. T. F., and Misk, R. Urinary glucuronic acid excretion in liver disease and the effect of a salicylamide load. Brit. med. J. 1959, 1, 337.

20. Corte, G., Jasmin, R., and Johnson, W. Effect of $\mathrm{N}$-acetyl-p-aminophenol on urinary glucuronide output and its implications in the prevention of urolithiasis. Canad. pharm. J. 1957, 90, 436.

21. Corte, G., and Johnson, W. Effect of N-acetyl-paraaminophenol on plasma levels of 17-hydroxycorticosteroids. Proc. Soc. exp. Biol. (N. Y.) 1958, 97, 751.

22. Williams, R. T. Detoxication Mechanisms. New York, Wiley, 1947.

23. Schmid, R., and Hammaker, L. Glucuronide formation in patients with constitutional hepatic dysfunction (Gilbert's Disease). New Engl. J. Med. 1959, 260, 1310.

24. Robinson, D., and Williams, R. T. Do cats form glucuronides? Biochem. J. 1958, 68, 23 P.

25. Glazko, A. J. Unpublished data.
26. Schmid, R., Axelrod, J., Hammaker, L., and Swarm, R. L. Congenital jaundice in rats, due to a defect in glucuronide formation. J. clin. Invest. 1958, 37, 1123.

27. Rich, M. L., Ritterhoff, R. J., and Hoffmann, R. J. A fatal case of aplastic anemia following chloramphenicol (Chloromycetin) therapy. Ann. intern. Med. 1950, 33, 1459.

28. Claudon, D. B., and Holbrook, A. A. Fatal aplastic anemia associated with chloramphenicol (Chloromycetin) therapy; report of 2 cases. J. Amer. med. Ass. 1952, 149, 912.

29. Smiley, R. K., Cartwright, G. E., and Wintrobe, M. M. Fatal aplastic anemia following chloramphenicol (Chloromycetin (B)) administration. J. Amer. med. Ass. 1952, 149, 914.

30. Loyd, E. L. Aplastic anemia due to chloramphenicol. Antibiot. et Chemother. (Basel) 1952, 2, 1.

31. Hargraves, M. M., Mills, S. D., and Heck, F. J. Aplastic anemia associated with administration of chloramphenicol. J. Amer. med. Ass. 1952, 149, 1293.

32. Erslev, A. Hematopoietic depression induced by Chloromycetin. Blood 1953, 8, 170.

33. Rubin, D., Weisberger, A. S., Botti, R. E., and Storaasli, J. P. Changes in iron metabolism in early chloramphenicol toxicity. J. clin. Invest. $1958,37,1286$.

34. Brown, A. K. Studies in the neonatal development of the glucuronide conjugating system (abstract). J. Dis. Child. 1957, 94, 510.

35. Lacson, P. S., and Waters, W. J. Urinary hexuronic acid determinations in prematures, newborns, and young infants (abstract). J. Dis. Child. 1957, 94, 510.

36. Lathe, G. H., and Walker, M. An enzyme defect in human neonatal jaundice and in Gunn's strain of jaundiced rats. Biochem. J. 1957, 67, 9P.

37. Brown, A. K., and Zuelzer, W. W. Studies on the neonatal development of the glucuronide conjugating system. J. clin. Invest. 1958, 37, 332.

38. Schmid, R. Jaundice and bilirubin metabolism. Arch. intern. Med. 1958, 101, 669.

39. McCance, R. A. Renal function in early life. Physiol. Rev. 1948, 28, 331.

40. Barnett, H. L. Kidney function of young infants. Pediatrics 1950, 5, 171.

41. Dorn, A., and Smith, M. H. D. Blood levels of palmitate ester of chloramphenicol in infants and children. J. Dis. Child. In press. 